\title{
Analysis of the Effects of Capacitances on Transformers in Transient Regimes by Finite Element Method
}

\author{
Yıldırım Özüpak \\ Dicle University Silvan Vocational School, Electrical and Energy Department, Diyarbakir, Turkey \\ E-mail address: yildirim.ozupak@dicle.edu.tr \\ ORCID numbers of author: \\ 0000-0001-8461-8702
}

Received date: 15.12 .2020

Accepted date: 29.01 .2021

\begin{abstract}
High currents occurring in transformers in transient state may cause the insulation materials to deteriorate. In this paper, the effects of the capacitance values between the winding and the core and between the windings on the transition of the lightning strike applied to the secondary side to the primary side of power transformers were analyzed. Transformer models were created in ANSYS@Maxwell-2D environment, which realizes a solution based on Finite Element Method (FEM). In simulation studies, a lightning impulse voltage of 1/100 $\mu \mathrm{s}$ was applied to the secondary side of the transformer with a special method. It has been observed that the change of the values of the capacitances between the windings in power transformers affects the amplitude of the primary lightning impulse voltage. With this study, the weak points of the insulation materials of transformers windings were determined and the electric field distribution was analyzed.
\end{abstract}

Keywords: Transformer, FEM, Lightning Impulse, Electric field, Maxwell-2D.

\section{Introduction}

Transformer models can be classified as low frequency [1] and high frequency [2] models according to the applied source frequency. Low frequency models are created by open and short circuit tests. Studies on low frequency model aim to model the nonlinear characteristics of the core [3]. High frequency model studies are carried out for fault detection of transformers and analysis of transient response [4]. In these models, which are analyzed based on high frequency, capacitances are added to the designs in addition to the parameters in the low frequency model. Since the effect of these capacitances at low frequencies is negligible, they are not included in the analysis. However, at high frequencies these capacitances significantly affect the transformer output.

Experimental tests have been performed on the current transformer in [3], among the studies on the lightning impulse response of transformers, and the lightning impulse response has been measured. With the test results, the equivalent circuit and transfer function of the transformer are established. The lightning impulse response measured with the simulation results with the model designed in ANSYS @ Maxwell environment was compared. In [4] the Frequency Response Analysis (FRA) method and an advanced model of the frequency response of a three-phase power transformer are presented to be used for fault detection. In 
[5], the power transformer and distribution transformer have been tested with FRA (Frequency Response Analysis) device and the equivalent circuits of the transformers have been removed. In [6], a simple modeling method based on measurement data in frequency domain, which can be easily applied in Electromagnetic Transients Program (EMTP) for power transformer, is tried to be presented. The important function of the model is that it can simulate the transient voltage transferred from one winding to another after lightning strike or switching.

In this paper, in the power transformer model in [5], the effect of the change of capacitance values on the primary side in case of a lightning strike applied to the secondary side has been investigated. Transformer models were created in ANSYS@Maxwell program. The electric field analysis of the model and the voltage distribution on the transformer are examined.

\section{Power Transformer Model}

[5] Study derives the power transformer model from study [6]. Experimental tests were carried out by applying $1.2 / 50 \mu$ s lightning strikes to a 300 MVA $415 / 15.75 \mathrm{kV}$ Y- $\Delta$ power transformer. Fig. 1 shows the power transformer model.

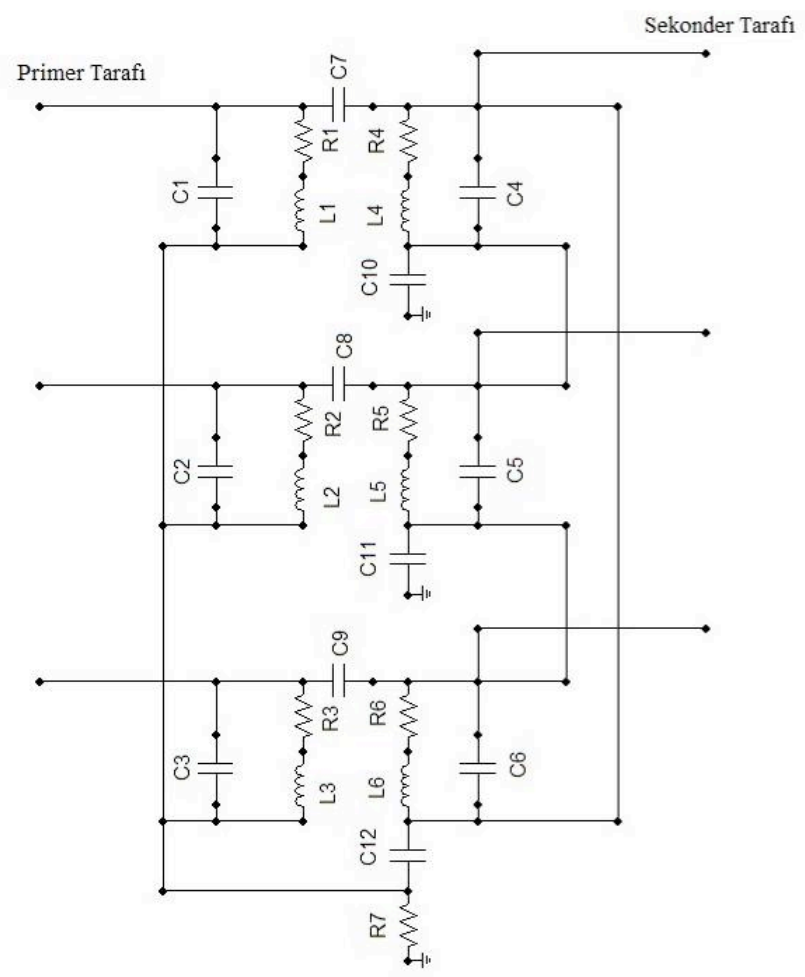

Fig. 1. High frequency power transformer model [5]

Copper losses are not taken into account in this model. $\mathrm{C}_{1}-\mathrm{C}_{6}$ coil capacitances; $\mathrm{C}_{7}, \mathrm{C}_{8}$ and $\mathrm{C} 9$ capacitances between windings; $\mathrm{C}_{10}, \mathrm{C}_{11}$ and $\mathrm{C}_{12}$ represent the capacitance between the neutral point and ground. $\mathrm{R}_{1}-\mathrm{R}_{6}$ and $\mathrm{L}_{1}-\mathrm{L}_{6}$ represent iron losses (magnetic circuit). $\mathrm{R} 7$ represents the neutral resistance.

Fig. 2 contains the test setup required for the measurement of the frequency response analysis (FRA) winding impedance of Primary - Earth $\left(\mathrm{V}_{\text {in }}\right)$ and Neutral - Earth $\left(\mathrm{V}_{\text {out }}\right)$ voltages [6]. By using the frequency spectrum of the winding impedance amplitude and angle, magnetic circuit resistance and inductance and winding capacitance can be obtained [6]. Since impedance is 
inductive at low frequencies, the winding capacitance can be regarded as open circuit and thus the magnetic circuit inductance can be determined from the measured reactance value. The winding capacitance is calculated using the inductance found in the first resonance frequency and low frequency calculation. In Eq. (1), the relation between voltages and winding impedance is given. In Eq. (2), the resonance frequency Eq. is given.

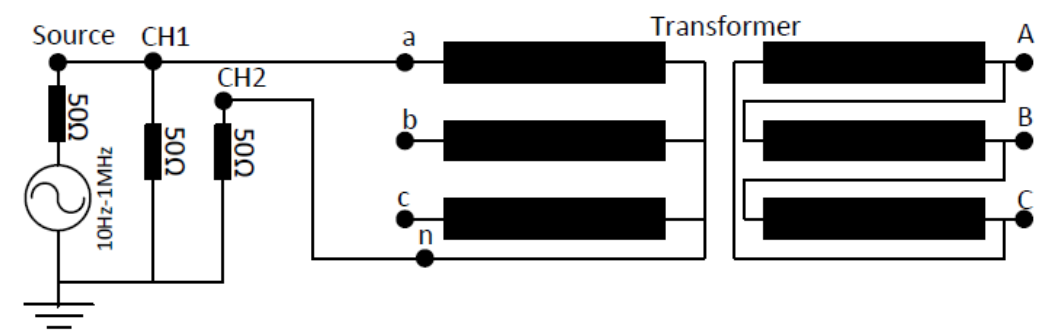

Fig. 2. Power transformer primary test setup [2]

$$
\begin{gathered}
Z_{s}=\frac{V_{\text {out }}}{V_{\text {in }}} .50-50=50 .\left(\frac{1-H e^{\theta}}{H e^{\theta}}\right), \frac{V_{\text {out }}}{V_{\text {in }}}=|H| \angle \theta=H e^{\theta} \\
f_{r}=\frac{1}{2 \pi \sqrt{(L C}}
\end{gathered}
$$

The $50 \Omega$ resistance in Eq. (1) is the internal resistance of the measuring device. The necessary parameters can be determined by creating the same test setup for the secondary winding. Secondary A phase test setup is given in Fig. 3 [2].

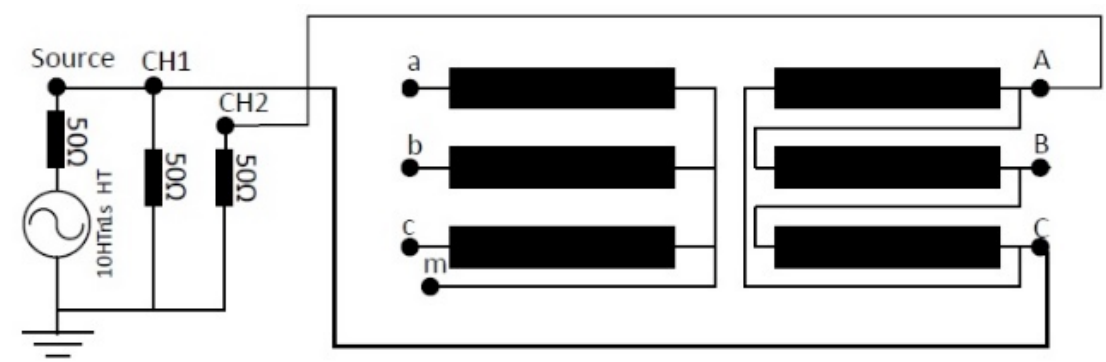

Fig. 3. Power transformer secondary test setup [2]

Primary and Secondary voltages were measured to determine the capacities between windings. In this study, it is stated that the frequency analysis of the primary and secondary voltages gives the impedance between the windings. At low frequencies, this impedance behaves capacitively and the capacitance value was obtained from the resistance [2]. Details of this test were not included in the study. The setup of this test is given in Fig. 4.

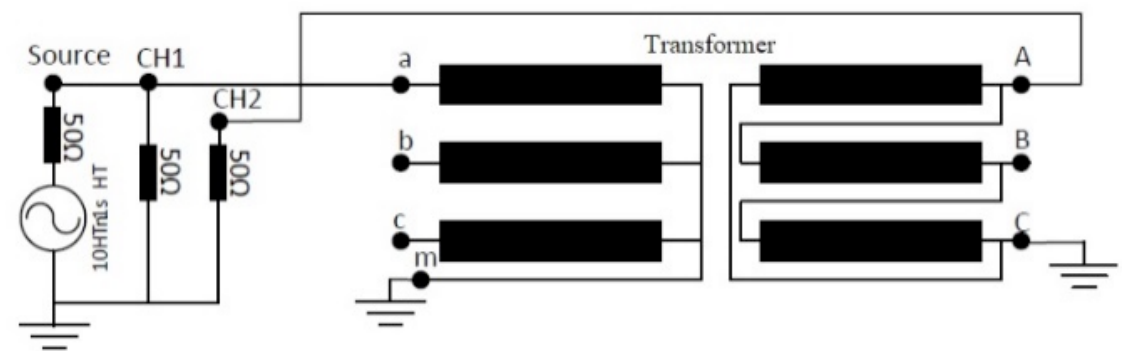

Fig. 4. Power transformer secondary-primary test setup [2] 
In the model in [1], the capacitive effect of the primary side is transferred to the secondary side as leakage inductance due to the inductive coupling between the windings. In the frequency analysis of the secondary winding, it is seen that the impedance is inductive at the second resonance frequency. From the impedance value at this frequency, the inductance; From Eq. (2) capacitances can be found.

The parameters of the tests and calculations of the power transformer model given in Fig. 1 are given in Table 1. In this study, calculation of magnetic circuit resistances is not included. It can be understood from the study that these resistors are not removed from the low frequency impedance.

\begin{tabular}{|c|c|}
\hline $\mathrm{R}(\Omega)$ & 0.001053 \\
\hline $\mathrm{L}(\mathrm{H})$ & 0.366 \\
\hline $\mathrm{C} 12(\mathrm{nF})$ & 70.08 \\
\hline
\end{tabular}

\section{Modeling of Transformer Using ANSYS@Maxwell}

Power transformer model in [5] were created in ANSYS@Maxwell environment and lightning impulse response was investigated. $170 \mathrm{kV} \mathrm{1/100 \mu s} \mathrm{lightning} \mathrm{impulse} \mathrm{voltage} \mathrm{was}$ applied to the power transformer. The simulation is set to $100 \mu \mathrm{s}$. Lightning impulse has been applied in the 1 st $\mu$ s to see the voltage wave precisely. Fig. 5 shows the power transformer model.
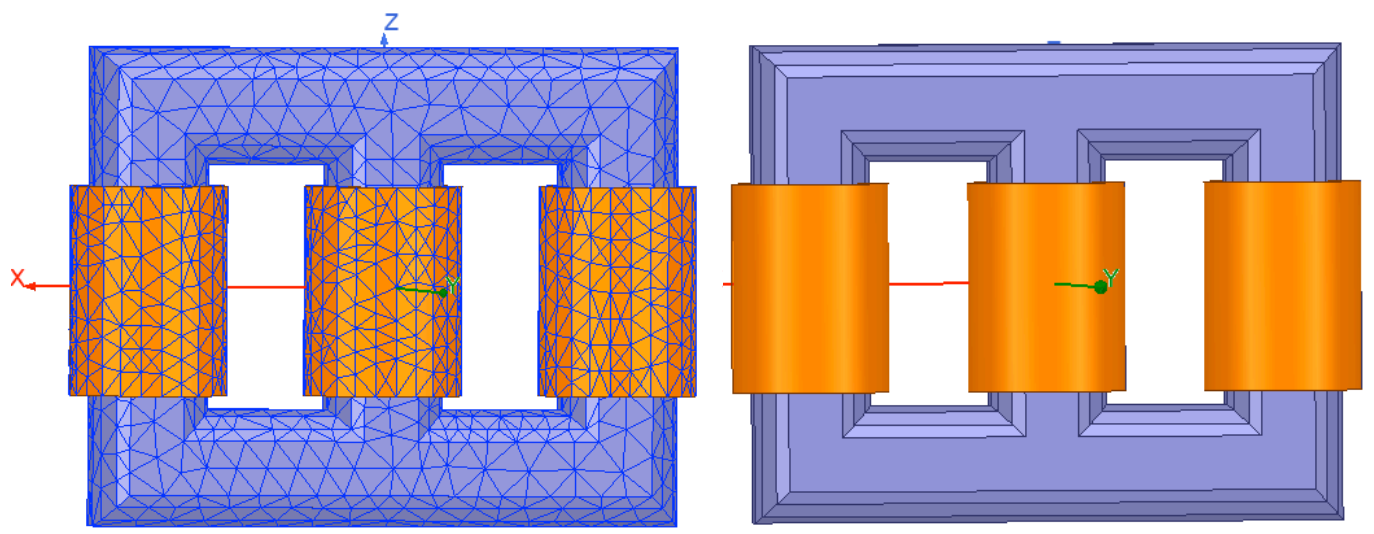

Fig. 5. Power transformer model

In the program environment, boundary conditions of the transformer model, geometric dimensions and the properties of all materials used are defined on the model. The core of the transformer is defined in the program environment with the $\mathrm{B}-\mathrm{H}$ curve of the magnetic material and thin sheets. The B-H curve, which is the magnetic property of the core material used, is given in Fig. 6. The geometric properties of the designed transformer are given in Table 2. 
Table 2. Geometric properties of the designed transformer

\begin{tabular}{cc}
\hline HV & $33.000 \mathrm{~V}$ \\
LV & $11.000 \mathrm{~V}$ \\
Core loss & $12.500 \mathrm{~W}$ \\
Load loss & $97.000 \mathrm{~W}$ \\
HV connection & Delta \\
LV connection & Star \\
HV turn number & 675 \\
LV turn number & 131 \\
HV current & $152 \mathrm{~A}$ \\
LV currunt & $785 \mathrm{~A}$ \\
\hline
\end{tabular}

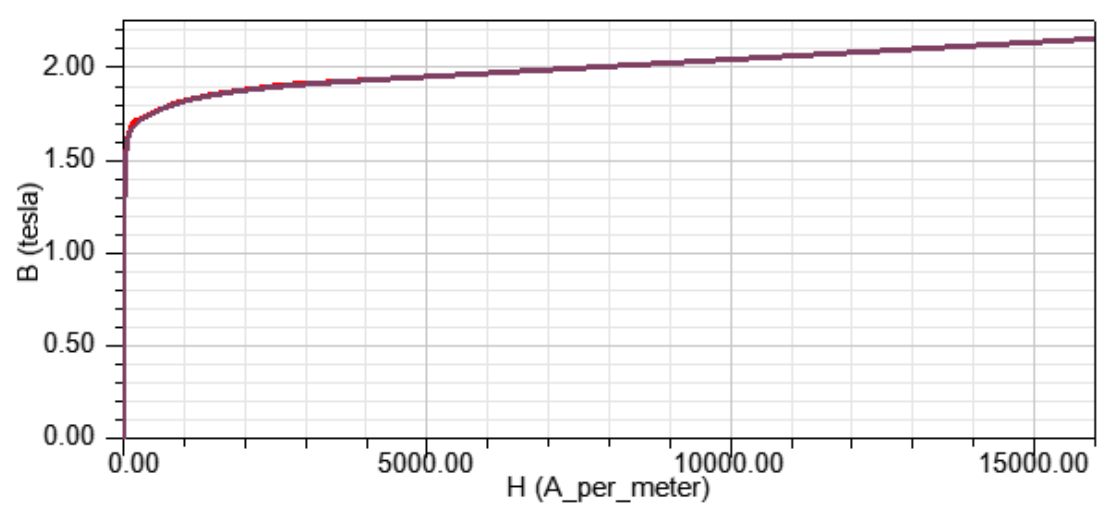

Fig. 6. B-H curve of core material

The graph of the lightning impulse voltage applied to the transformer windings in the program environment is presented in Fig. 7.

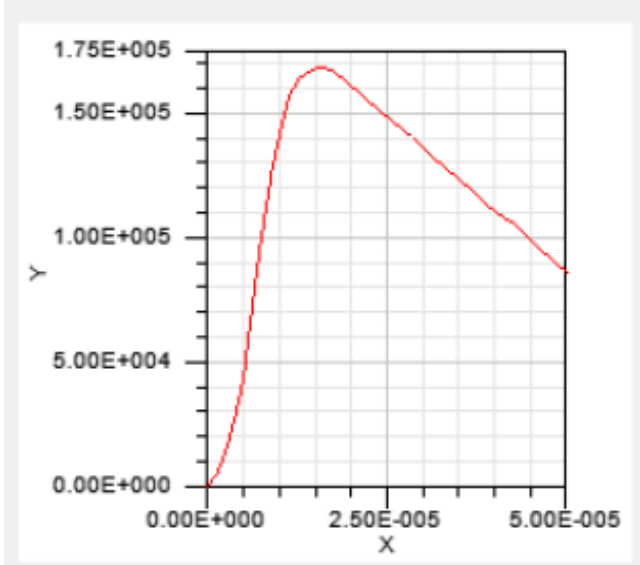

Fig. 7. Lightning impulse voltage applied. 


\subsection{Analysis of the model}

In Fig. 7, the form of the voltage applied to the primary A phase of the power transformer, and the form of the voltage generated in the secondary. The electric field distribution caused by a lightning strike is given in Fig. 8. The electric field voltage curve is given in Fig. 9.

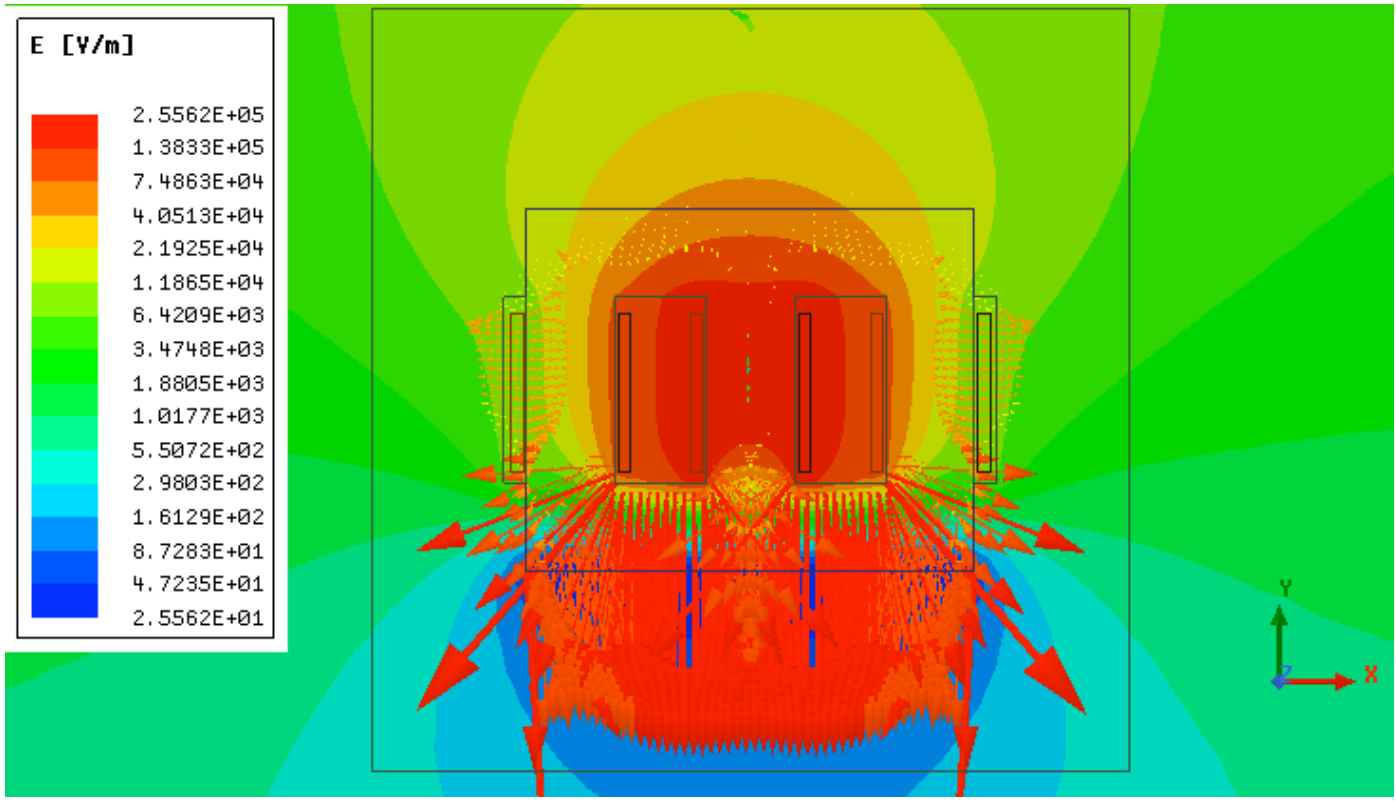

Fig. 8. Lightning-impulse electric field.

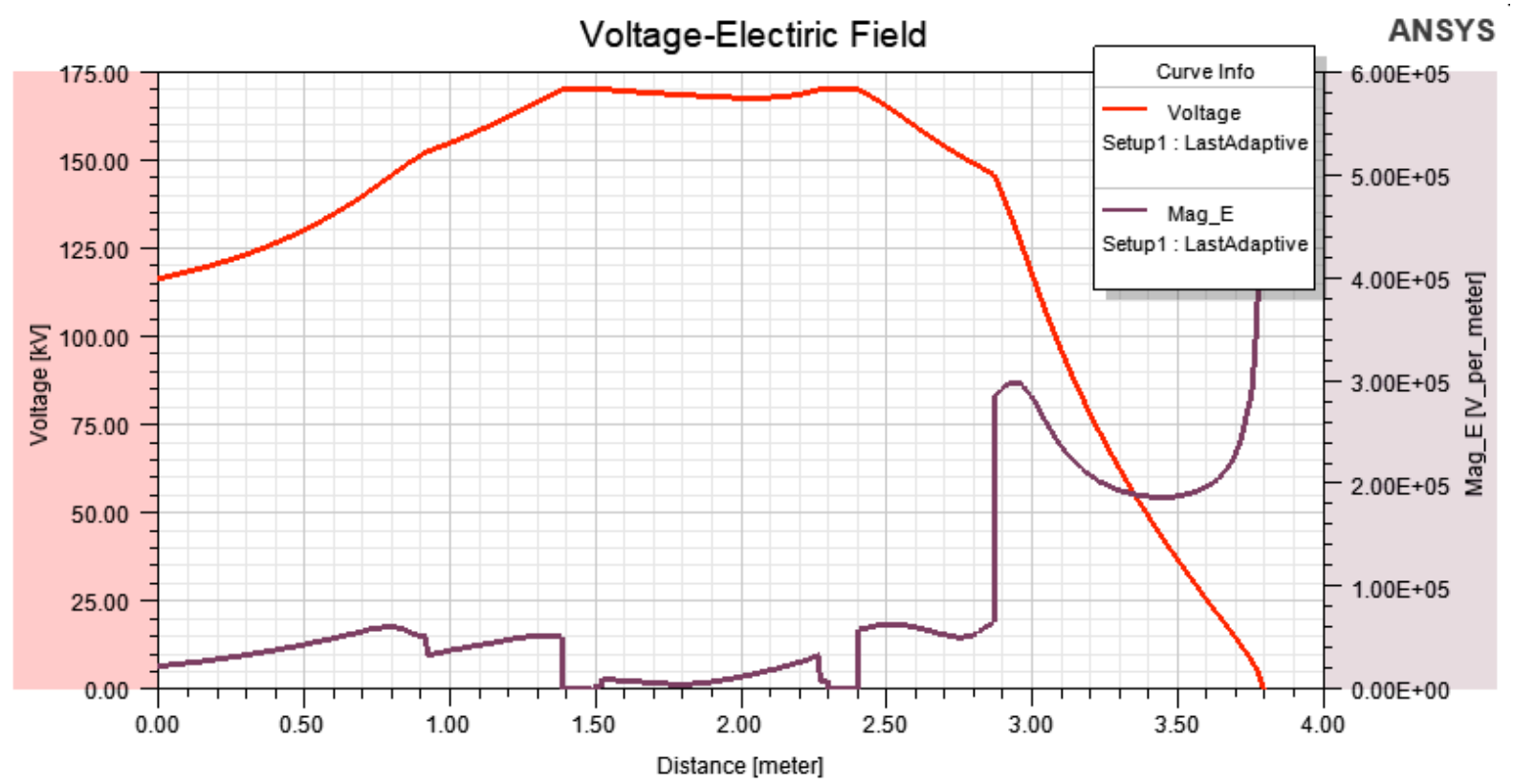

Fig. 9. Electric field-voltage relationship

The amplitude of the electric field value occurring in the transformer and the amplitude of the electric field strength are presented in Fig. 11 and Fig. 12, respectively. 


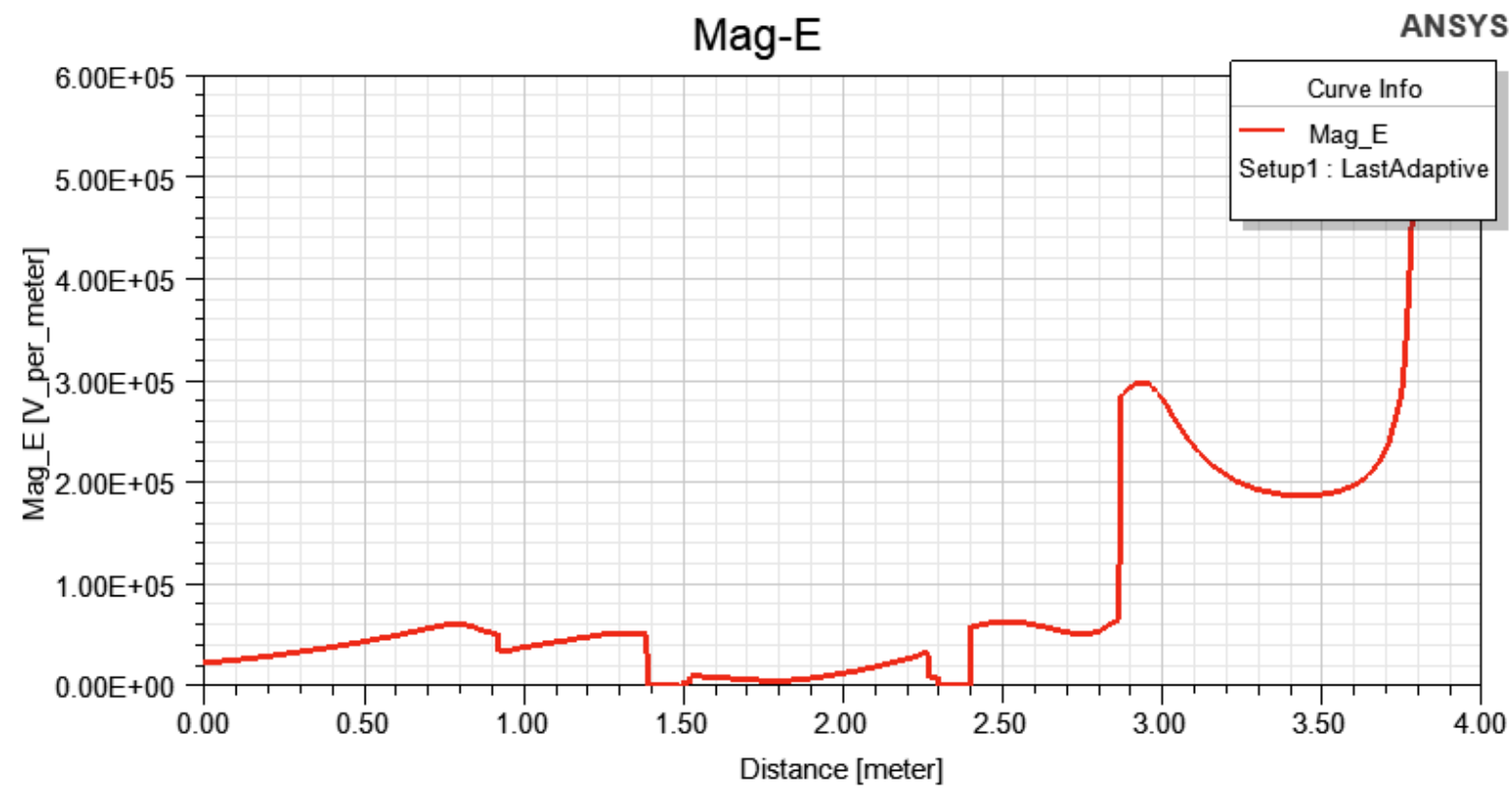

Fig. 10. Magnitude of electric field on primary winding.

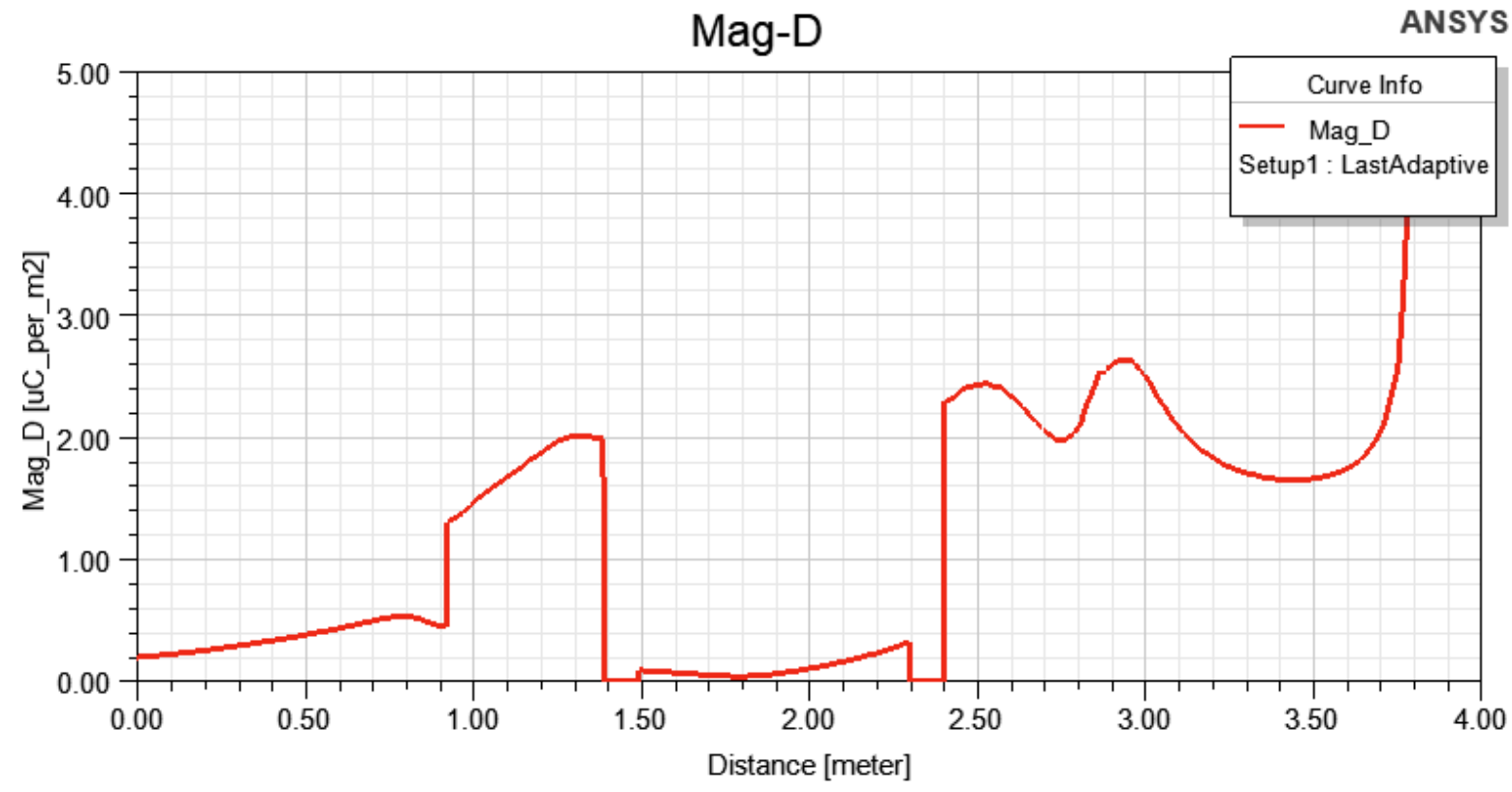

Fig. 11. Magnitude of density field

The energy released due to the electric field in the transformer windings and the stresses occurring at the edges of the transformer windings are given in Fig.s 12 and 13. 


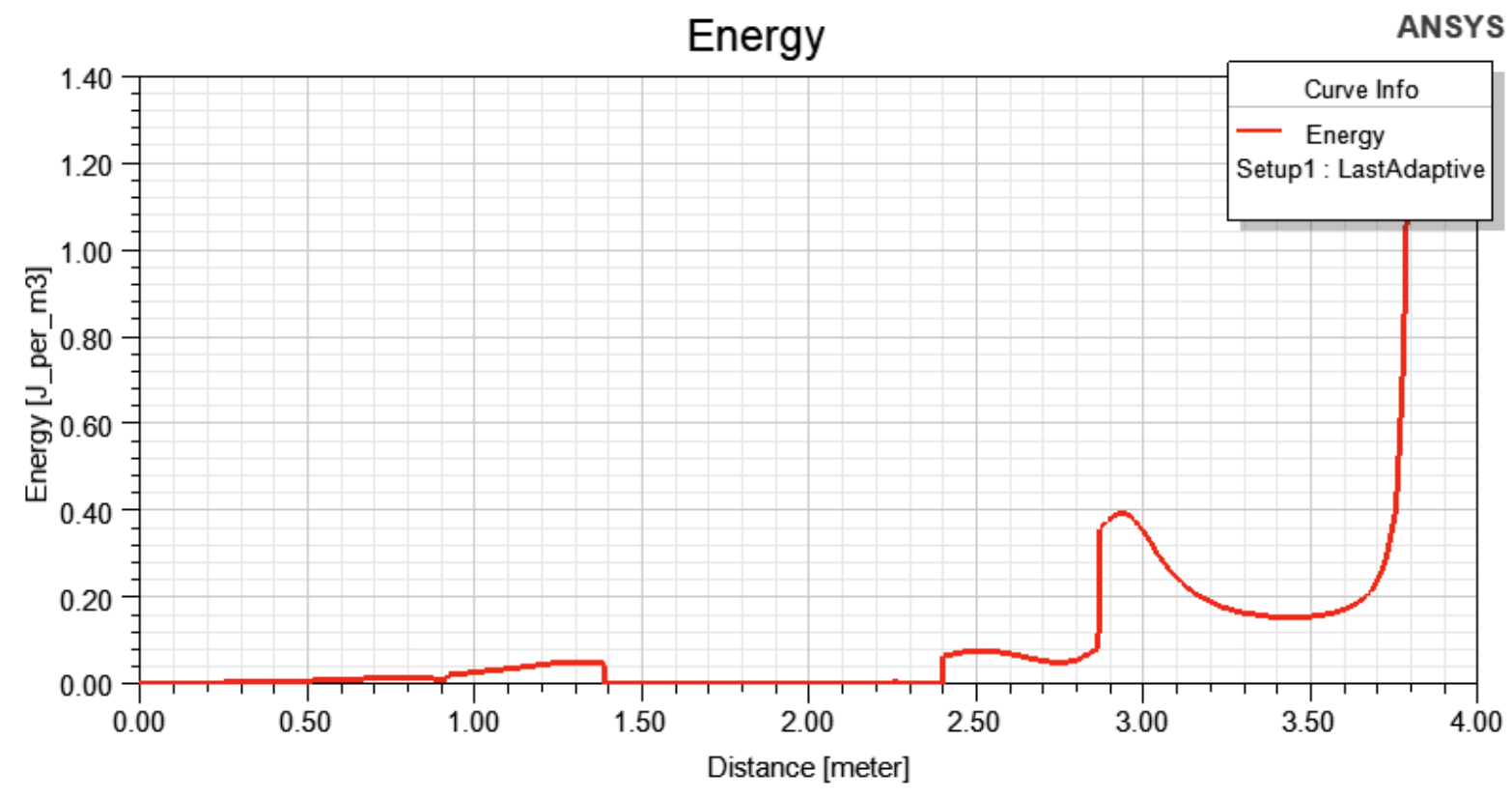

Fig. 12. Energy storage on winding

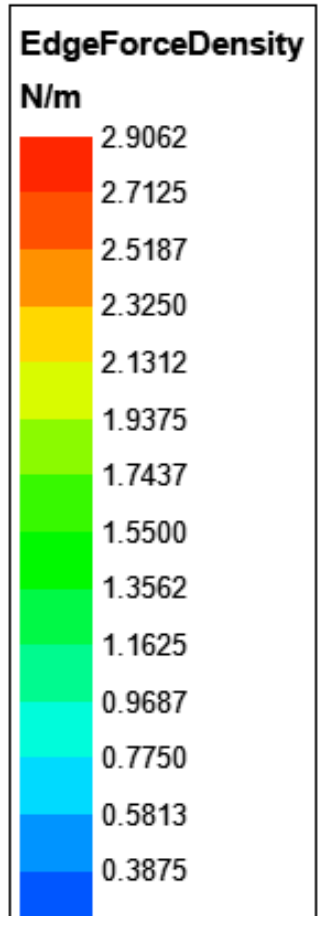

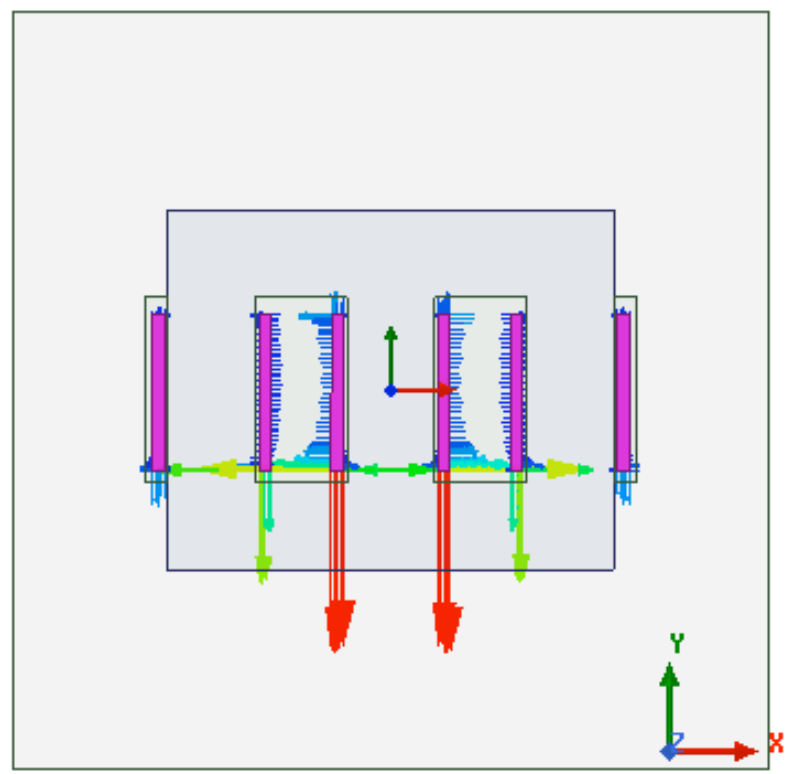

Fig. 13. Edge force density on winding

The result of the lightning voltage in the secondary winding is consistent with the lightning pulse applied. Critical areas that could cause degradation in the insulating materials between the primary and secondary windings have been identified. The electric field distribution in critical regions on the insulating material of the two-dimensional model is also shown. 


\section{Conclusions}

In the power transformer model, it has been observed that changing capacitance values increase and decrease the amplitude of the voltage. In the conflict, it is also seen how the electric field of the transformer under transient regime causes the strain on the insulation material. Lightning impulse is a very important phenomenon for all electrical power systems due to surge surge. This is why the lightning analysis is equally important to the power problem. In this article, the lightning impulse voltage applied to the transformer during the lightning-strike, the electric field of the transformer and the voltage distribution are presented with simulation results. Critical areas between primary and secondary windings that may cause degradation in insulating materials are shown in three dimensions. The electric field distribution in critical regions on the insulation material of the two-dimensional model is also shown. This article presents the use of the integral Eq. approach in computing the electric field. This approach is used to solve a numerical example to verify the applicability of a transformer to calculate the electric field. The system of Eq.s is solved using boundary element methods. Results are compared to those of a commercial FEM software and are in good agreement.

\section{Acknowledgments}

This study was supported by Inonu University Scientific Research Projects Coordination Unit. Project Number: FBA-2017-639.

\section{References}

[1] Akdağ, M., Mamiş, M.S, Investigation the Effect of Capacitances on Lightning Impulse in Transformers, Güç Sistemleri Konferansi, 15-16 November, Ankara, 2018.

[2] Morched, A., Marti, L., Ottevangers, J., a high frequency transformer model for the EMTP, IEEE transactions on power delivery, 8(3), 1615-1626, 1993.

[3] Özüpak, Y., Mamiş, M.S, Teke, İ.H., Electromagnetic field and total loss analysis of transformers by finite element method, International Journal of Engineering And Computer Science, 8(1), 24451-24460, 2019.

[4] Özüpak, Y., Mamiş, M.S, Realization of electromagnetic flux and thermal analyses of transformers by finite element method, IEEJ Transactions on Electrical and Electronic Engineering, 14(10), 1478-1484, 2019.

[5] Subedi, D., Lightning induced over-voltages in power transformer and voltage spikes in connected load, Master Thesis, Aalto University, Helsinki, Finland, 2017.

[6] Shirvani, A., Malekian, K., Schmidt, U., Schufft, W., A new power transformer model over wide frequency range for EMTP, 45th International Universities Power Engineering Conference (UPEC2010), 1-6, 2010.

[7] Sabiha, N.A., Lightning-induced overvoltages in mediumvoltage distribution systems and customer experienced voltage spikes, PhD Thesis, Aalto University, Helsinki, Finland, 2010.

[8] Shareghi, M., Phung, B.T., Naderi, M.S., Blackburn, T.R., Ambikairajah, E., Effects of current and voltage harmonics on distribution transformer losses, International Conference on Condition Monitoring and Diagnosis (CMD), 633-636, 2012

[9] Soh, T.L.G., Said, D.M., Ahmad, N., Nor, K.M., Salim, F., Experimental study on the impact of harmonics on transformer, IEEE 7th International Power Engineering and Optimization Conference (PEOCO 2013), 686-690, 2013 